\title{
NarRation in medical CARE. Selected aspects OF NARRATIVE MEDICINE IN PSYCHIATRY
}

\author{
Patrycja Zurzycka ${ }^{A, B, D, E, F}$, Katarzyna Wojtas A,B,D,E,F $^{A}$
}

Department of Clinical Nursing, Institute of Nursing and Midwifery, Faculty of Health Sciences, Jagiellonian University Medical College, Krakow, Poland

\section{Authors' contribution:}

A. Study design/planning $\bullet$ B. Data collection/entry $\bullet$ C. Data analysis/statistics $\bullet$ D. Data interpretation $\bullet$ E. Preparation of manuscript $\bullet$ F. Literature analysis/search $\bullet$ G. Funds collection

\author{
Address for correspondence: \\ Dr Katarzyna Wojtas \\ Department of Clinical Nursing \\ Institute of Nursing and Midwifery \\ Faculty of Health Sciences \\ Jagiellonian University Medical College \\ 25 Kopernika St., 31-501 Cracow, Poland \\ e-mail: katarzyna.wojtas@uj.edu.pl \\ SUBMITTED: 29.07 .2021 \\ ACCEPTED: 23.08 .2021 \\ DOI: https://doi.org/10.5114/ppiel.2021.110454
}

\begin{abstract}
Narrative in medical practice is a way to explore the nature of the disease in the face of the patient's uniqueness and individuality, regardless of the diagnosed disorder or disease. The narrative approach provides patients with a representation of their own story, a demonstration of interest on the part of their treatment team, and a positive relationship with the highest level of health care provision, always in relation to the patient's current health and life situation. The use of narrative medicine is important in forming relationships with patients or when professional work becomes a source of burnout and lack of perceived satisfaction. Aim of the study was to present selected issues related to the practice of narrative in medical care, including the care of patients with mental disorders. Thirty-three selected original papers were thoroughly analysed. All works were written in the period 2011-2020 and could be characterized as demonstrative or research papers and case studies. Medline, PubMed, SAGE, and other databases were used.

Literature analysis confirms the presence of narrative medicine, including in the field of psychiatry. Researchers emphasize the importance of narrative in creating relationships with patients, shaping both their activity and involvement, as well as with members of the therapeutic team. In practice, narrative involves professionals expressing empathy, using narrative techniques, and being accountable when interacting with patients who discover themselves. The importance of narrative in the care of patients with various disorders, including mental disorders, is significant in providing care that is consistent with patients' expectations and needs.
\end{abstract}

Key words: patient, narrative in medical care, patient's history.

\section{INTRODUCTION}

Narrative medicine has been defined by Rita Charon as the ability to recognize, assimilate, interpret, and respond to the stories of others [1-3]. In the practice of medicine, it helps us to understand the nature of disease or disorder by taking into account the needs, values, personality, and uniqueness of the patient in the face of diverse relationships and dependency systems [4-7]. Narrative also helps us to understand how the patient experiences the disease and all its consequences [2, 5, 8, 9]. Incorporating narrative into daily practice contributes to the provision of quality care that is consistent with the patient's expectations $[4,10,11]$. This is possible by ensuring relevant health information and medical interventions, taking into account the patient's individuality $[3,4,12]$.

Narrative in medicine means, above all, the opportunity for the patients to present (tell) their own history and to show them attention and care [13-15]. Authentic interest in the other person, perceiving him/her in a broader perspective than just through the biomedical dimension of his/her functioning, emphasizes the context and complexity of relations and influences occurring in the patient-therapeutic team $[4,6]$ and patient-social relations [8]. The interactions and relationships formed as a result of conversation, as well as its very context and course, significantly influence the creation of the story being told, including the one that arises while providing everyday care (clinical encounter narrative) [13-15]. Narrative in medical care may have a healing and therapeutic role, so to speak - it enables the patients to tell their own history of illness, gives value and meaning to their statements, and emphasizes the validity of active listening [16]. Moreover, narrative promotes authentic understanding and helps to establish an empathic 
therapeutic relationship $[4,10,11]$, strengthens the patient-staff relationship, enhances the capacity for reflection $[6,13,16]$, and influences both the personal and professional development of therapeutic team members [16].

There are 3 basic components in narrative medicine: attentiveness, representation, and affiliation. Attentiveness refers to an increased focus of attention on the content, form, or circumstances of a message. It requires openness to perceptual impressions of the storyteller as well as verbal and nonverbal messages. Representation usually takes a descriptive form that summarizes the story that has been told as well as heard (applies to both teller and listener). Affiliation is associated with deep and attentive listening as well as knowledge derived from representation [17].

An important aspect of practicing narrative medicine is reflexivity and reflection. Reflection includes consideration of individualized needs, self-reflection and self-awareness, reflection of action, its consequences, and reflection of taking action in the future [4]. Reflexivity, on the other hand, is understood as the ability to observe ourselves with the same methods that are used to study phenomena. Reflexivity requires analysis of own actions, critical insight, and evaluation of our own role in co-creating reality [17]. Some of the patients' stories are simple and easy to understand. However, others are more complex or perhaps told in a particular way that requires more information, further research, and specialized interpretation. Encountering a patient requires insight and reflection on the part of health care providers about their role and their own impact on the resulting interaction [13]. Each person has his/her own story, which is a sequence of interrelated events and facts that can be presented in the form of a subjectively shaped vision of life that is both an expression of identity and a factor in its formation [7]. Self-talk allows one to get to know oneself better and to give meaning to the things that have a non-obvious impact on functioning. Being able to look at our own lives and the factors that shape them illustrates and reminds us of often overlooked or forgotten aspects of our own story [7].

This paper is based on selected scientific literature available in the Medline, PubMed, and SAGE databases and ACADEMIA.EDU, The Lancet, Ejournals.eu, Longdom Publishing SL, RUJ, Biblioteka Nauki, and CEEOL websites. Thirty-three selected original papers were thoroughly analysed. All works were written between 2011 and 2020, and they could be characterized as demonstrative or research papers and case studies.

The aim of this paper is to present selected issues related to the practice of narratives in medical care, including the care of patients with mental disorders.

\section{NARRATIVE IN PATIENT CARE}

Individual and unique narratives enable the expression of individual experiences, beliefs, values, and preferences resulting from both the patient's personality and socio-cultural conditions of functioning. Narrative-based care encourages patients not only to describe events that are important to them and not necessarily directly related to their current medical condition [4], but also to explore the dynamics of the patient-treatment team relationship in the context of relational and diverse threads [7].

Narrative care involves a genuine interest in the patient's person and sensitivity to their needs, not judging their attitudes, values, or choices, and demonstrating flexibility and willingness to make changes in the therapeutic relationship. Medical staff should actively listen to patients, provide opportunities to express needs and expectations, and motivate and support them to participate in decisions about the care and therapeutic process $[4,6]$. Narrative care focuses not only on biomedical issues such as symptom specificity, diagnostic management, side effects, and complications of treatment, but also on issues related to psychological and emotional needs (e.g., anxiety, worry), social circumstances, and expectations of the care provided. Considering only the somatic dimension of a patient's functioning limits the ability to fully understand how they experience their illness [9]. Disease symptoms or diagnostic test results deprived of interpretation are often insufficient to make a diagnosis, which is an interpretive process aimed at trying to understand the patient's narrative $[4,8]$. It is also important to assess the patient's behaviours related to adaptation to the disease and treatment, and to assess the family, social, occupational, and psychosocial problems that occur relating to the impact of disease on the patient and their loved ones, the need to change their social roles, reduced economic status, available and received support, family relationships, and spiritual issues [4].

Three main areas can be distinguished in patient narratives. The first is the restitution narrative, in which patients assume that their health will return to normal (pre-disease state). Another area is the chaos narrative related to the patient's experience of loss of control over their lives and the sense of burden resulting from the disease, especially chronic disease, including, e.g., pain sensations. This narrative relates to the process of taming the situation as a result of disease and treats the difficulty in expressing experiences or experiences related to it [18]. The third area is the search narrative, in which patients view their illness as a challenge and a spiritual journey. Additionally, they express hope that the experience of illness will become valuable to them in some way [14]. Professionals in the health care system can be tasked with helping the patient integrate the story with the 
search narrative and facilitate the development of new solutions and plans and alternative hopes for the future $[14,17]$.

\section{NARRATIVE COMPETENCE}

Narration, as an important source of knowledge, provides information not only about the symptoms of disease and ailments experienced by the patient, but also information that goes beyond the biomedical understanding of disease. In addition to the use of medical knowledge necessary in the treatment process, professionals should know and understand the patient's narratives; narrative competence should be used at every stage of contact with the patient $[3,4,12]$. Narrative competence means the ability to thoroughly "read" the patients' history, and it determines the acquisition of knowledge about the problem [2]. They are defined as professional skills of health care professionals, which should be based on empathy, reflection, professionalism, and credibility. These competencies are also described as the ability to analyse the story presented - the story structure, taking multiple perspectives, understanding metaphors and hidden meanings of narratives [4]. In the narrative approach one "follows" the patients, paying attention to their fears, expectations, feelings, emotions and reactions, ideas related to the course of disease, and other aspects of human functioning. It is also important to observe and interpret the patient's body language and communication skills [5]. The demonstration of narrative competence by health care providers means emphasizing the role of the patients' stories in their daily functioning and providing patient-centred medical interventions [4]. In turn, a lack of narrative competence can result in decreased effectiveness of clinical work due to an inability to perceive the patients' narratives while providing clinical care [3].

Practical tips for incorporating narrative into everyday health care practice include showing interest in the patient, not interrupting them (allowing them to finish their thoughts), asking open-ended questions [19], and exploratory questions, such as: What does this mean to you? [4]; How has the illness affected your life and relationships?; What is it like to find out that you have the disease?; In what ways has your illness changed your life the most?; What are your hopes and fears?; and What is important in your life? [14]; Tell me more about it; Is there anything else?; Is there anything you worry about?; What worries you the most?; Has this ever happened before?; What else was going on at the time?; What do you think about...?; What do others think about...?; How do you feel [or react] when...?; What does it mean to you?; What do you think might cause...?; How would you describe...?; and How would you explain...? [13]. It is also possible to have a conversation based on ask- ing questions to encourage the patient to reflect and make a possible change in their thinking or actions, which may sound like the following: How else can you explain...?; Are there any other possibilities?; Let's suppose...; What would happen if...?; If you had a magic wand, what would you do?; What must happen for the situation to change?; If the situation did change, what would happen then?; and What would happen if nothing changed? [13]. Moreover, it is very important to assure the patient about one's readiness to help, to explain the importance of knowing the patient's needs, to show active listening, to notice changes in the patient's statements, and to create hypotheses about the possible meanings of his/her statements. It is also important to assess the patient's perception and presentation of the problem that led him/her to seek help. For health care professionals, this provides a basis for asking detailed questions in the medical interview [17]. If it is difficult to determine why a patient is seeking help, health care professionals should ask the patient about it and ask themselves why this patient is seeking help at this time [19].

The implementation of narrative medicine principles also includes respecting silence during the conversation, allowing the patient to take an initiative, observing nonverbal communication, and ensuring that the conversation continues if the conversation must be interrupted due to circumstances. In practicing narration, it is important to beware of judging, making fixed assumptions, and rushing to solve the problem [19].

The basic as well as postgraduate education of health care professionals should include passing on knowledge and skills, as well as presenting attitudes that aim to perform care with a holistic approach. This sometimes requires breaking out of the traditional clinical paradigm that focuses solely on the biological realm of patient functioning and recognizing how a patient's illness affects their functioning, expression of emotions, performance of social roles, or maintenance of relationships [11]. The narrative approach cannot be learned quickly and exclusively by acquiring a set of narrative techniques. Moving from a conventional form of practice to a narrativeoriented practice requires persistence, attentiveness to habits and routines, and ongoing self-reflection. Learning narrative skills begins with listening to and exploring the patient's history. It requires a willingness to hear the story and a desire to understand it, and refinement of these skills occurs over the course of listening to and analysing multiple narratives [19].

\section{SELECTED ASPECTS OF NARRATIVE IN PSYCHIATRY}

Psychiatry seems to be an area where the narrative aspect is particularly important [4, 20,21], because all 
types of mental disorders can be better understood through narrative inquiry. Opinions are present in the literature that refer to the lack of presence of narrative. This situation results in clinicians referring only to symptoms indicative of the clinical unit, treating the mental disorder and not the person [22].

Narrative in psychiatry confirms that there are many possibilities for telling the story of mental health and there is no single specific way. Clinical dialogue, on the other hand, shows a new point of view of the patient's problems. It should be emphasized that narrative in this field of medicine does not reduce the validity of the biological approach [23], and it shows a positive relationship with the outcome of clinical examination and diagnosis. Narrative psychiatry does not aim to negate or disqualify other knowledge and research [24]. In its realm, narrative also captures the process of communicating with the patient and the fact that the patient's narrative is not only telling, but also experiencing and responding [25]. The narrative helps to formulate the problem at hand; thus, the construction of questions starting with "how" is more important than formulating questions with "why" [22].

Narration in psychiatry draws attention not only to the existing psychopathology, but also to a broader aspect of the patient's functioning and undertaken activities, to the whole of his/her life, because mental health disorders are only a fragment of the patient's full knowledge [25]. During contact with the patient, it is particularly important to pay attention to the content of the stories told by them, because thanks to this it is possible to correctly read their entire context and assess their needs and emotions, and this has a direct impact on making effective interventions [21].

The patient with a mental disorder can communicate a lot about their childhood, disease symptoms, reaction to the disease, work experiences, and social support in his story. The patient's narrative may also include an area related to physical health. If the patient has comorbid somatic illnesses, attention must be paid to them as well, because only then is it possible to undertake of an integrated nature, referring to the holism of care [22]. Patient histories also allow for a broader context for assessing available and received social support and its sources, rather than simply confirming or denying the possession of such resources. This is of particular importance in defining the role of the patient's support persons and determining what their support consists of [22].

Therapeutic narrative is also of great importance in the conducted therapies because the heard story allows the therapist to direct a new point of view of the person asking for help and to indicate new possibilities of coping with the current situation. In the opinion of some specialists, patient narratives consti- tute a fundamental element in medical practice [26], and in the opinion of others they can be helpful in forensic opinions [27].

The specificity of mental illness forces a change in the current way of the patient's functioning and experiencing, it introduces a sense of chaos, uncertainty, and confusion. Therefore, the proposed narrative in the form of expressive writing is very often considered as a source of knowledge about the disease and allows for ordering of thoughts and experiences that accompany the disease. The way it is presented, especially at the beginning of treatment, can be difficult, incomprehensible both for the patient him/ herself and his/her environment, and even for the psychiatrist, and it requires proper interpretation [25].

Narrative in practice treats the patient as a human being and allows the patient to express his/her own point of view, which can be important in providing guidance for further management [28], and this seems to be extremely valuable in intervening with people with mental disorders. Emphasizing the importance of the patient's statement in the professional exchange of information provides evidence of changes in medicine [29], treating patients as expert of knowledge on mental illness [25], and furthermore, the psychiatrist adopts an attitude of collaboration with those seeking help [30]. In addition, it is evidence of presenting a way of understanding and interpreting the current situation and reality not only by the patient but also by the medical personnel [25].

In the approach of narrative medicine, it is important to emphasize the fact that psychiatrists can hear the most personal stories of their patients, and therefore they are even more responsible for the relationship with their clients [31]. In shaping the complex patient-physician relationship, patient acceptance, the importance of patient involvement, and activity is emphasized, because conscious participation in the treatment process affects the broader therapy and quality of care [32].

Narrative has its importance in the contact between the patient and the psychiatrist, the patient and the therapist, and the patient and the nurse. This emphasizes the nurse's role in the therapeutic team.

Through narrative, nurses working with individuals with mental disorders can explore the whole experience and understand the person's history in relation to the environment in which they function. The nurses' narrative techniques (to some extent intuitively) that enable discussions revealing patients' motivations and problems confirm their professionalism [22].

The patient's telling of their own story is a key to building their sense of dignity, worth, and subjectivity and often proves that life satisfaction can be achieved despite illness [25]. The use of narrative medicine is valuable in cases of difficulties in forming relationships with patients, emergence of professional burn- 
out, or lack of perceived professional satisfaction. In practice, it also means developing interpersonal skills and professionalism [33], which are essential when it comes to dealing with people with mental disorders. Following the principles of narrative medicine can be helpful in meeting current health challenges and can bring tangible benefits to the medical field of psychiatry [21].

\section{SUMMARY}

The benefits of practicing narrative medicine include improvement in communication and patienttherapeutic team relationships, refinement of medical information obtained through a standardized interview or analysis of test results, understanding of certain beliefs, attitudes, or behaviours expressed by the patient, as well as increased mutual trust, empathy, and commitment to shared decision-making.

The narrative approach also improves relationships within the therapeutic team and positively influences the quality of care provided, allows for identification and understanding of mistakes made (and avoiding them in the future), and increases job satisfaction by reducing the risk of burnout. In addition, it contributes to the development of professionals and their awareness of possible prejudices, stereotypes, and fears.

Patients rate the clinical competence of professionals highly, but high scores are also attributed to interpersonal skills, active listening, showing empathy and engagement, which are significantly related to narrative care. Therefore, it is possible and advisable to use an approach that combines both clinical (EBM) and narrative (NBM) medicine in medical practice; this combination has a positive impact on the effectiveness, quality, and satisfaction of medical care.

\section{CONCLUSIONS}

Narrative medicine determines the quality of patient care based on an active communication process using narrative techniques.

The narrative approach breaks the focus on the traditional clinical paradigm, requires empathy, responsibility, and openness towards the patient, and it emphasizes the patient's subjectivity and active involvement in the treatment process, in which the interventions taken are based on knowledge from the patients' accounts.

\section{Disclosure}

The authors declare no conflict of interest.

\section{References}

1. Muneeb A, Jawaid $\mathrm{H}$, Khalid $\mathrm{N}$, et al. The art of healing through narrative medicine in clinical practice: a reflection. Perm J 2017; 21: 17-013.
2. Murphy JW. Primary health care and narrative medicine. Perm J 2015; 19: 90-94.

3. Charon R. At the membranes of care: stories in narrative medicine. Acad Med 2012; 87: 342-347.

4. Chu SY, Wen CC, Lin CW. A qualitative study of clinical narrative competence of medical personnel. BMC Med Educ 2020; 20: 415.

5. Zaharias G. Narrative-based medicine and the general practice consultation: Narrative-based medicine 2. Can Fam Physician 2018; 64: 286-290.

6. Yang N, Xiao H, Cao Y, et al. Does narrative medicine education improve nursing students' empathic abilities and academic achievement? A randomised controlled trial. J Int Med Res 2018; 46: 3306-3317.

7. Potoniec M, Syzek H. Wstęp do wydania polskiego. (Kon) tekst medycyny: o języku medycyny narracyjnej. In: Charon R, DasGupta S, Hermann N, et al. (Eds.). Medycyna narracyjna. Teoria i praktyka. Medycyna praktyczna, Kraków 2020; 35-34.

8. Murphy JW, Franz BA, Schlaerth C. The role of reflection in narrative medicine. J Med Educ Curric Dev 2018; 5: 2382120518785301.

9. Lewis B. Narrative medicine and contemplative care at the end of life. J Relig Health 2016; 55: 309-324.

10. Hurwitz B, Charon R. A narrative future for health care. Lancet 2013; 381: 1886-1887.

11. Pentiado JA Jr, De Almeida HO, Amorim FF, et al. Love and the value of life in health care: a narrative medicine case study in medical education. Perm J 2016; 20: 98-102.

12. Liao HC, Wang YH. Storytelling in medical education: narrative medicine as a resource for interdisciplinary collaboration. Int J Environ Res Public Health 2020; 17: 1135.

13. Zaharias G. What is narrative-based medicine? Narrativebased medicine 1. Can Fam Physician 2018; 64: 176-180.

14. Ragan SL, Kanter E. Learning the patient's story. Semin Oncol Nurs 2017; 33: 467-474.

15. Egnew TR. A narrative approach to healing chronic illness. Ann Fam Med 2018; 16: 160-165.

16. Rosti G. Role of narrative-based medicine in proper patient assessment. Support Care Cancer 2017; 25 (Suppl 1): 3-6.

17. Charon R, DasGupta S, Hermann N, et al. (Eds.). Medycyna narracyjna. Teoria i praktyka. Medycyna Praktyczna, Kraków 2020.

18. Szubert M. Narracyjność choroby i nadejście medycyny jutra. Kultura Wspótczesna 2019; 4: 76-92.

19. Zaharias G. Learning narrative-based medicine skills: Narrative-based medicine 3. Can Fam Physician 2018; 64: 352-356.

20. Chrzczonowicz A. Narracja w psychiatrii - teoria, zastosowanie, związki ze zdrowiem psychicznym. Post Psychiatr Neurol 2011; 20: 283-289.

21. Dosani S. The value and benefit of narrative medicine for psychiatric practice. BJPsych Bull 2020: 1-3.

22. Hall JM, Powell J. Understanding the person through narrative. Nurs Res Pract 2011; 293837: 1-10.

23. Lewis B. Perspectives. The art of medicine. Taking a narrative turn in psychiatry. Lancet 2014; 383: 22-23.

24. Bradley L. Narrative and psychiatry. Curr Opin Psychiatry 2011; 24: 489-494.

25. Grzybek M. Obraz psychozy w autobiograficznej twórczości literackiej osób chorujących psychicznie. Zeszyty Pracy Socjalnej 2020; 25: 283-295.

26. Dein S. Narratives and healing: implications for psychiatry and psychotherapy. Anthropol 2016; 4: 162.

27. Drukteinis AM. Forensic historiography: narratives and science. J Am Acad Psychiatry Law 2014; 42: 427-436. 
28. Zurzycka P, Radzik T. Medycyna narracyjna - zarys problematyki. Probl Pielęg 2015; 23: 428-432.

29. Zabielska M, Żelazowska-Sobczyk M. „Pamiętam, zdarzyło się to w sobotę rano, około 10”. Fachowe publikacje medyczne oparte na relacjach pacjentów i lekarzy. In: ChojnackaKuraś M (Ed.). Medycyna narracyjna. Opowieści o doświadczeniu choroby w perspektywie medycznej i humanistycznej. Wydawnictwo Uniwersytetu Warszawskiego, Warszawa 2019; 127-141.

30. Carrey N. Practicing psychiatry through a narrative lens. working with children, youth, and families. In: Brown C, Augusta-Scott T (Eds.). Narrative therapy: making meaning, making lives. SAGE Publications Inc., Thousand Oaks - London - New Delhi 2007; 77-102.

31. Wendt C. Revisiting narrative medicine's place in psychiatry. Am J Psychiatry Resid J 2020; 16: 9-12.

32. Antoszewska B. Patient in the physician's perspective. Narrative research. Seminare. Poszukiwania naukowe 2019; 40: 117-131.

33. Andre F, Lijoi AF, Tovar AD. Narrative medicine: Re-engaging and re-energizing ourselves through story. Int J Psychiatry Med 2020; 55: 321-330. 